\title{
A FORMAÇÃO POLÍTICA DO PROFESSOR E UMA INTRODUÇÃ̃ À TEORIA DA REPRODUÇÃO CULTURAL NO ENSINO FORMAL
}

\author{
SILVINO MORAIS BARROS*
}

\section{RESUMO}

Este artigo faz uma introdução à teoria da reprodução cultural no ensino formal, além de contextualizar a formação política e o trabalho do professor no Brasil. Essa abordagem evidencia uma aproximação entre Pierre Bourdieu e Florestan Fernandes, respectivamente.

PALAVRAS-CHAVE: educação, formação política, professor, reprodução, sociologia.

The teacher's political formation and an introduction to the theory of cultural reproduction in formal education

\section{SUMMARY}

This article makes an introduction to the Theory of Cultural Reproduction in Formal Education besides putting into context the Political Formation and teacher's work in Brazil. This approach makes evident an approximation to Pierre Bourdieu and Florestan Fernandes.

KEY WORDS: education, political formation, reproduction, teacher, sociology.

\section{INTRODUÇÃo}

No que se refere à reprodução cultural, o presente artigo é uma aproximação entre duas personalidades da sociologia da educação: Flores$\tan$ Fernandes e Pierre Bourdieu. O brasileiro e o francês, respectivamente, por serem sociólogos preocupados com a violência simbólica que é praticada nas instituições de ensino de seus respectivos países, representam fontes de informação aos envolvidos com o sistema de ensino e sua significância em sociedade.

A sociologia da educação volta-se, tanto para a condução do ato pedagógico nas instituições de ensino, como para a reprodução cultural em sociedade, dado o conflito existente na imposição de violência simbólica pelo ato pedagógico, ato este que está presente no sistema de ensino e contido na aceitação involuntária dos alunos e, principalmente, na perspectiva

\footnotetext{
* Graduado em Ciências Sociais (Universidade Federal de Goiás) e Ciências Econômicas (Universidade Católica de Goiás).

<e-mail: economiaesociedade@hotmail.com.br >
} 
míope de parte dos docentes. Os professores praticam a imposição de seu arbitrário cultural, cuja origem é o conjunto de idéias culturais do seio familiar e do meio ou instituiçóes de ensino de que fazem parte. O resultado disso é a reprodução dos planos de ensino, anos a fio, sem alterações significativas na estrutura do texto pedagógico.

Desse modo, este artigo introdutório versa sobre a formação política do professor e sobre a reprodução cultural no sistema de ensino, inicialmente trazendo à superfície do raciocínio a condição socioeconômica limitante do estudante brasileiro, num contexto em que o desempenho escolar é dependente da condição socioeconômica da família.

Em seguida, trata da condição de classe do professor brasileiro, enquanto agente capaz de transformar o sistema de ensino, com base na perspectiva eclética de Florestan Fernandes, em que o professor pode revolucionar seu meio ou instituição de ensino. Assim, além de reiterar a importância do professor para o sistema de ensino, ressalta uma ação pedagógica transformadora, eclética, multidisciplinar, eficiente e psicologicamente sã no processo de ensino e aprendizagem, ou seja, reafirma uma ação dotada de clareza e consciência da prática arbitrária da avaliação pedagógica, por exemplo, em sala de aula. Para isso, apresenta-se um breve histórico da participação política dos professores num processo histórico de conscientização de classe no Brasil.

Por último, aproximam-se os dois referidos autores, exaltando a importância de sua localização geográfica e temporal, o que, no entanto, não é considerado como uma barreira à possível aproximação epistemológica. Para isso, trata-se do que se refere à reprodução cultural no sistema de ensino, tendo como esteio a sociologia da educação. Vale assinalar, de antemão, que Florestan Fernandes e Pierre Bourdieu são peregrinos da senda da educação. Em 1970, Boudieu escrevia $A$ reprodução, contribuindo para a consciência dos franceses sobre a violência do arbitrário cultural no sistema de ensino. Em 1985, Florestan percorria mais uma vez os auditórios das Faculdades de Educação no Brasil, depois de décadas de luta pelo ensino eclético e democrático, após a abertura política no país.

Assim, traz-se à tona o fato de que o arbitrário cultural é imposto pelos professores ou agentes de transformação social, em sala de aula, por exemplo, na reprodução de planos de ensino e programas disciplinares, diante de idéias culturais reproduzidas historicamente nas escolas do Brasil na época da colônia. Para essa reprodução ocorrer, um fator preponderante foi necessário, qual seja, a compreensão equivocada, por parte dos docen- 
tes, do papel significante do sistema de ensino e de qual seria a atuação desse(a) professor(a) em sociedade. Ao se observar que a falta de recursos financeiros destinados ao sistema de ensino ainda fecha escolas ou as mantém precariamente abertas, pode-se notar que permanece latente a consciência coletiva dos professores e estudantes para a concepção de democracia ou ecletismo no sistema de ensino.

\section{A INFLUÊNCIA DA CONDIÇÃO SOCIOECONÔMICA NO RENDIMENTO ESCOLAR: A REVOLUÇÃo CULTURAL DE BOURDIEU}

Pierre Bourdieu foi responsável, nos anos 60 , por uma resposta original e empiricamente engajada para a solução dos problemas das desigualdades escolares, principalmente na França. Trata-se da noção de que a escolarização exercia um duplo papel na superação do atraso econômico e da construção de uma sociedade mais justa, com características de ser uma sociedade meritocrática, moderna, centrada na razão e nos conhecimentos científicos, e democrática, caso da sociedade fundamentada na autonomia individual. Assim, a visão funcionalista, que considerava o mérito individual ou dom como causa do bom desempenho escolar, foi superada após os estudos realizados por Bourdieu.

Em estudo recente, Nogueira e Nogueira (2002) mencionam haver uma falsa igualdade no sistema de ensino, uma vez que os indivíduos não competem em condiçóes de igualdade uns com os outros. Para tanto, dizem que uma profunda crise no sistema de ensino, nos anos 60, expressou a estagnação do sistema praticado nas instituições de ensino após a II Guerra Mundial, e países como a Inglaterra, a França e os Estados Unidos empenharam-se na realização de grandes pesquisas "quantitativas", apontando a condição social do estudante como uma das causas do seu rendimento escolar.

Conceitos de classe social, etnia, sexo, e outros indicadores de condição social, aos poucos, tomaram, então, o lugar de uma noção funcionalista do sistema de ensino na sociedade. Esse fato, juntamente à massificação do ensino após os anos 60, levou à desvalorização dos títulos acadêmicos e escolares, ocasionando uma "revolução científica", de que fala Pierre Bourdieu, em seu livro A reprodução.

Um dos principais meios utilizados para a legitimação dos privilégios sociais em sociedade, segundo Bourdieu, é o sistema de ensino. Para Nogueira e Nogueira (2002), o sociólogo francês foi capaz de perceber 
uma inversão na perspectiva que se tinha, até os anos 60, do sistema de ensino, ou seja, no lugar de democratizar, o sistema de ensino passa a manter e legitimar os privilégios sociais, num processo cruel de reprodução das desigualdades sociais.

Assim, a herança familiar, juntamente com suas implicações escolares, a escola e o processo de reprodução das desigualdades sociais (ambas são as teses centrais desenvolvidas por Bourdieu, tendo em vista que o sociólogo francês proclamou a função do capital cultural no sistema de ensino francês) são a causa do desempenho escolar do estudante. Essa noção é composta, segundo Bourdieu (1982), do capital econômico, do capital social e do capital familiar. Vale dizer, o capital cultural é a soma desses capitais, e as funçóes de um, de acordo com o autor, seriam barreiras e pontes existentes no caminho do estudante na senda do sistema de ensino.

O capital a que se refere Bourdieu é o que distingue o êxito do fracasso escolar. O sucesso ou desempenho favorável na escola, por parte do estudante, é correlacionado aos fatores citados, fatores esses que fomentam a vida escolar do estudante.

O papel da família e o papel da escola somam-se numa equação, cuja discussão teórica em sociologia desenvolve-se à medida que se chega à perspectiva de reprodução do capital intelectual em sociedade. Família e escola, cada qual em sua condição simbólica, são fontes de informações tidas por Bourdieu como essenciais à compreensão do cenário da educação social. Família, escola e o papel das estruturas sociais no comportamento humano possibilitam, assim, questionar as atitudes e os comportamentos individuais em sociedade.

Metodologicamente, Bourdieu centra-se na teoria crítica sociológica, cuja localização encontra-se não no objetivismo (lógica e causalismo funcionalista) nem no subjetivismo (relativismo e interacionismo simbólico), mas no termo central dessa intercessão. Em $A$ reprodução, um estudo inovador, Bourdieu (1982) afirma haver um conjunto de capitais dispostos, competindo entre si, no cenário do sistema educacional (capital econômico, capital social, capital familiar = capital cultural). O capital econômico e o capital social representariam os meios auxiliares à acumulação do capital cultural e de sua reprodução em sociedade, na maior parte dos casos, mas não uma regra geral. Desse modo, o desempenho favorável do estudante, na escola, dependeria da conjunção dos fatores (capitais), segundo Bourdieu. 
Caso haja mais e menos capital econômico, e capital social, haverá restrição ao acesso, por parte do estudante, a certos ambientes e objetos, mas isso não o impediria de desempenhar, satisfatoriamente, seu papel de estudante na escola. Na medida em que a escola se tornasse uma instituição neutra a possibilidade de se obter ótimo desempenho, por meio de dom e mérito pessoal, seria possível.

Com $A$ reprodução, Bourdieu (1982) contribuiu para que a noção de neutralidade no sistema de ensino fosse combatida na comunidade acadêmica e científica. Formalmente, a escola tende a ser neutra. Sociologicamente, porém, Bourdieu pôde comprovar a falta de neutralidade nos critérios de verificação de aprendizagem, posto que dizem respeito a uma ação pedagógica orientada e carregada de valor, ou melhor, de violência simbólica e imposição de um arbitrário cultural.

Os estudantes assistem às mesmas aulas, portanto, espera-se que tenham as mesmas chances de desempenho. No entanto, para alguns, haveria maior facilidade de compreensão das exigências pedagógicas da escola, "muitas vezes implícitas". Os professores praticariam, segundo Bourdieu (1982), algo distinto da verificação da aprendizagem, vale dizer, um julgamento social em detrimento de uma "avaliação pedagógica" eclética.

As críticas feitas a Bourdieu pela comunidade científica referem-se à falta de aprofundamento (ou escolha metodológica) no estudo da microssociologia - caso de famílias, indivíduos, escolas específicas e professores concretos. $\mathrm{O}$ estudo do habitus familiar, das diferenças entre famílias (e não classes sociais) e dos contextos de escolarização ficou à margem do estudo macros sociológico de Bourdieu (Nogueira e Nogueira, 2002).

\section{A AÇÃo PEDAGÓGICA TRANSFORMADORA E A CONSCIÊNCIA POLÍTICA DO} TRABALHO DO PROFESSOR: O ECLETISMO EM SALA DE AULA

Fernandes (1986, p. 31), ao referir-se à condição de classe do professor brasileiro, num processo histórico de construção de identidade - que é útil ao amadurecimento da consciência política desse agente da Educação -, diz que ele

[...] [o professor] precisa se colocar na situação de um cidadão de uma sociedade capitalista subdesenvolvida e com problemas especiais e, nesse quadro, reconhecer que tem um amplo conjunto de potencialidades, que 
só poderão ser dinamizadas se ele agir politicamente, se conjugar uma prática pedagógica eficiente e uma ação política da mesma qualidade.

O citado autor lembra que o sociólogo brasileiro não dispõe de condiçōes satisfatórias de pesquisa nas Universidades, ao empreender projetos ligados à área da Educação. E afirma:

Para que ela [a pesquisa] se desenrole de maneira produtiva, é mister contar com certas condições internas e externas de labor intelectual, que assegurem normalmente: 1) a observância estrita de caracteres formais do conhecimento científico; 2) bases adequadas de organização institucional do trabalho científico, quer na esfera da pesquisa e da elaboração teórica, quer na da aplicação; 3) motivação consistente contínua do comportamento dos diferentes tipos de trabalhadores intelectuais, engajados com tarefas relacionadas com a obtenção, a propagação ou a utilização prática dos dados ou descobertas da ciência; 4) entrosamento plástico e eficiente do sistema de instituiçôes científicas com a sociedade inclusiva, de modo a promoverem rendimentos máximos na satisfação de necessidades materiais ou morais, preenchidas pelo saber científico, pela tecnologia científica e pela educação baseada na ciência na moderna civilização mecânica e industrial. (Fernandes, 1963, p. 14)

Convém assinalar que o brasileiro Florestan Fernandes foi proeminente sociólogo e militante das causas sociais, além de pesquisador que expunha temas/dilemas da sociedade com singularidade e destreza ímpar. Sua representatividade, como pesquisador, foi sentida em diversos países e suas obras lidas por pessoas em diversos ambientes, acadêmicos ou não.

Nesse sentido vale destacar seu artigo intitulado "A formação política e o trabalho do professor" (Fernandes, 1986), cuja linguagem expressa a importância do embate travado na área da Educação no Brasil, e por isso contribuiu eficientemente para a consciência de "classe" dos professores.

Assinale-se também a realização do Seminário Itinerante, cujo título temático era Dependência Econômica e Cultural, Desenvolvimento Nacional e Formação de Professores, desenvolvido na Universidade de São Paulo, em 1985, no qual Florestan Fernandes compareceu e expôs sua posição a respeito da condição social e política do trabalho de professor no Brasil. Trata-se de evento que representou uma espécie de marco na concepção de ação pedagógica transformadora no processo de ensino e na formação de professores no Brasil, na medida em que suscitou críticas e 
alusões necessárias à mudança na condição de trabalho do pesquisador e professor brasileiro - isso, segundo época e condição pessoal do autor enquanto marxista.

O Seminário Itinerante (Fernandes, 1985) é base para debates políticos acerca da condição do professor (como profissional) e do estudante brasileiro (como elo de ligação entre a instituição de ensino e a sociedade) em eventos subseqüentes. As três preocupaçôes centrais do Seminário Itinerante foram:

1) a tradição cultural brasileira e os limites do horizonte cultural do professor;

2) a correlação entre a atividade do professor e o caráter político/ prático do agente;

3) e a seguinte proposição: o que uma pessoa que se diz marxista pensa, quando se coloca diante de um assunto como esse?

Com relação à primeira parte (tradição cultural brasileira e os limites do horizonte cultural do professor), há uma exposição da condição hierarquizada da sociedade brasileira, no que se refere ao processo de educação, além de uma percepção da separação entre cidadão/cientista/professor no mesmo contexto social. Isso, à medida que a dominação cultural se perpetuava, desde a colonização portuguesa, no Brasil. Assim, desde a colônia, atribuía-se ao professor o papel de reproduzir e transmitir um arbitrário cultural, oriundo e destinado a perpetuar e renovar a dominação por parte das elites políticas, econômicas e sociais do país.

Ainda no que se refere à tradição cultural brasileira, no tocante ao processo de ensino e aprendizado, tinha-se que a cultura cívica era ausente do processo de ensino. Sequer havia uma relação democrática entre professor e sociedade. $\mathrm{O}$ professor brasileiro, até então, era um agente das elites políticas, econômicas e sociais, além de estar ausente da cultura cívica da nação. Ou melhor, não havia uma compreensão, por parte dos professores em geral, da condição política de suas atividades, enquanto agentes conscientes, inseridos no contexto social das instituições de ensino. No mais, os professores não tinham a noção da possibilidade de fazerem uma mudança no contexto social brasileiro, por extensão, fazer uma revolução educacional no Brasil.

No que concerne à segunda parte (correlação entre a atividade do professor e o caráter político/prático do agente), denota-se que uma 
emancipação dos oprimidos, por meio da educação, seria uma saída útil à mudança no processo de dominação cultural exercida pelas elites brasileiras. Vale dizer, desde que o conjunto de instituiçôes de ensino, juntamente com a classe de professores e, também, as elites culturais, interagissem numa prática política voltada para o ensino e aprendizado.

Fernandes (1986) aponta, também, limites ideológicos que se tornam mecanismos a impedir uma ação pedagógica eficaz no Brasil. Ação cuja meta de se "dissolver" o ensino e aprendizado no Brasil, de forma criativa e de forma eclética, seria alcançada quando os estudantes fossem envolvidos no processo de transformação encabeçado pelos professores. Não importa que tais professores sejam conservadores, reformistas e revolucionários, pois o Brasil condicionou, historicamente, o assistencialismo em detrimento da ação pedagógica eficiente no ensino e aprendizado nacional.

A segunda parte da exposição é tida como cabal. Nela menciona-se haver, ao longo do tempo - desde a colônia -, a deterioração das escolas, em todos os níveis do ensino. $\mathrm{O}$ autor condiciona à consciência política o meio. A consciência política seria eficaz para a luta pela independência do sistema de ensino nacional. $\mathrm{Na}$ medida em que houvesse uma conciliação entre as ciências, num ato multidisciplinar, tais como a Filosofia, as Ciências Sociais, as Artes etc., haveria uma "prática pedagógica eficiente e voltada para o ecletismo em sala de aula”.

O Seminário é norteado pela proposição imposta pelo autor, qual seja, "o que uma pessoa que se diz marxista pensa, quando se coloca diante de um assunto como esse?” (Fernandes, 1986, p.14). Tal Seminário é esclarecedor da condição de Florestan Fernandes como militante da mudança social (a revolução). No entanto, o termo revolução não era compreendido, literalmente, quanto à sua etimologia. $\mathrm{O}$ que se vislumbrava era a possibilidade de uma revolução, aos moldes políticos, no sistema de ensino e na formação de professores. À medida que houvesse a preocupação com uma "ação pedagógica e políticas públicas orientadas na redefinição dos valores institucionalizados no ensino formal brasileiro, haveria ecletismo no processo de ensino e aprendizado".

A utopia do sistema de ensino sensacional, e totalmente neutro, é falha, segundo Florestan Fernandes. Conforme se tornarem mais críticos - e voltados para a mudança de paradigmas sociais existentes e incrustados no sistema de ensino brasileiro - a voz e o peso dos atos dos professores, conseqüentemente, menos ideal se torna tal relação entre professores e estudantes. 
Portanto, quando professores forem mais valorizados e melhorarem seu nível de escolarização (pós-graduação) e remuneração, unirem-se como classe organizada e transformadora, haverá maior difusão da "ação pedagógica eficiente e transformadora do sistema de ensino", rumo à ação pedagógica eclética no processo de ensino e aprendizagem. Uma ação pedagógica eclética é aquela que contribui para a construção do processo de ensino e aprendizagem, mas uma construção multidisciplinar. Como a diversidade está em voga na tendência dos Parâmetros Curriculares Nacionais, os professores têm, portanto, ao se dedicarem ao ensino e aprendizagem, de complementar o quadro de agentes ecléticos de transformação nas escolas.

\section{Perspectivas comuns}

Em Fernandes (1986) e em Bourdieu (1982), duas preocupações centrais e comuns podem ser definidas, quais sejam: a de que o ensino formal não é neutro e a de que a condição social influencia o rendimento escolar do estudante.

Os dois cientistas sociais se colocam diante de dilemas sociológicos enquanto agentes caracterizados como seres plurais ou ecléticos (nem objetivamente nem subjetivamente; mas, na soma e na diferença entre as correntes ideais da sociologia). No que tange à aproximação entre os autores, tema central deste artigo, a intenção foi descrever a condição de intervenção e inovação metodológica a partir dos dois pesquisadores.

Aos que lêem a súmula do Seminário Itinerante (Fernandes,1986) e $A$ reprodução (Bourdieu, 1982) na perspectiva de obterem mais subsídios para a compreensão dos dilemas da sociologia da educação, cabem algumas advertências:

1) Olhar a sociologia como ciência, a qual mergulha nas "profundezas do mar sem fim" dos dilemas sociais, captando a crueza do sistema de ensino formal, de Brasil e França (as respectivas peculiaridades entre os sistemas de ensino formal dos dois países os distinguem, enquanto sistemas de ensino formal, e as mesmas peculiaridades tendem a aproximá-los como sistemas de interação simbólica de violência pedagógica arbitrária);

2) Olhar a educação como um meio e não um fim em si mesma, com a meta de se reunir grupos de ciências e técnicas capazes de 
aprimorar, de construir, de inovar as maneiras de se desenvolver o processo de ensino e aprendizado;

3) Por fim, propor a união de ambas as restrições (1 e 2) (na sociologia crítica e na educação construtiva; a crítica construtiva, no sistema de ensino formal, favorece a noção de ecletismo no ato docente).

Pode-se afirmar que, entre Fernandes (1986) e Bourdieu (1982), há uma singularidade aproximativa, qual seja, ambos são pesquisadores imersos em sociedades que possuem sistemas de ensino formal heterogêneo, sistemas amplamente arbitrários e simbolicamente caracterizados como institucionalizados - agências normalizadas pela sociedade. A diferenciação, no entanto, apenas aparece na localização geográfica de Florestan (no Brasil) e Bourdieu (na França).

Abaixo do Rio Grande, desde o México até a Argentina e o Chile, somos, depois de rápidas lutas pela independência, no século dezenove, um grupo de nações mergulhadas nesse processo de organização e integração, com maiores ou menores progressos, todas lutando para efetivar as indispensáveis incorporações e assimilações sem a tragédia da guerra civil que marcou a sociedade americana. Nem sempre há completa percepção da dificuldade da tarefa. O velho vício da duplicidade mantém-nos, por vezes, no estado de descuidado enleio, com que escamoteamos a nós próprios a verdadeira realidade.Chegamos, em nossos hábitos, sob alguns aspectos, esquizofrênicos, a criar um tipo específico de revolução, misto de teatro e de espasmo de violência, a revolução insincera, a "revolução sul-americana". É que a sociedade, ainda constituída na base das divisões e estratificações sociais até ontem toleradas, mas hoje, com novos processos de comunicação [...] não ganhou completa consciência dos sinais que prenunciam as convulsões integradoras [...] Nem o espanhol nem o português que aqui aportaram traziam propósitos de criar, deste lado do Atlântico, um mundo novo. Encontraram um mundo novo, que planejaram explorar, saquear e, assim enriquecidos, voltar a Europa. (Teixeira, 1976, p. 8)

Para que uma revolução sul-americana no sistema de ensino possa ocorrer, no Brasil, é necessário romper as relaçôes formais entre os sistemas institucionais, tais como o sistema de ensino. A função de estudiosos que se voltam à solução dos dilemas da educação é mostrar à sociedade, na qual se inserem, que há problemas comprometendo o ensino e a apren- 
dizagem das pessoas em vida escolar. A tradição escolar brasileira é, por vezes, seletiva e preconceituosa. Para isso ser verdade, é preciso acabar com a reprodução cultural dos hábitos e práticas pedagógicas nas escolas. $\mathrm{O}$ sociólogo e o pedagogo, por exemplo, podem colocar o dedo nessa ferida e provocar uma reação de transformação ou mudança. Ambos os cientistas são agentes que exercem um poder de persuasão e, por meio de tal tipo de ação, são capazes de construir um cenário que não seja esquizofrênico e nem reprodutor de erros, ao longo da história.

\section{REFERÊNCIAS}

BOURDIEU, Pierre. A reprodução: elementos para uma teoria do sistema de ensino. 2. ed. Rio de Janeiro: Livraria Francisco Alves, 1982.

FERNANDES. Florestan. A sociologia numa Era de Revolução Social. 2. ed. São Paulo: Nacional, 1963.

A formação política e o trabalho do professor. In.: CATANI, Denice Bárbara et al. (Orgs.). Universidade, escola e formação de professores. 1. ed. São Paulo:Brasiliense, 1986.

NOGUEIRA, C. M. Martins; NOGUEIRA, M. A. A sociologia da educação de Pierre Bourdieu: limites e contribuições. CEDES - Educação e Sociedade, Campinas, v. 23, n. 78, 2002.

TEIXEIRA, Anísio. Valores proclamados e reais nas instituiçôes escolares brasileiras. 1. ed. Rio de Janeiro: Centro de Serviços Gráficos do Instituto Brasileiro de Geografia e Estatística, 1976.

Recebido em: 14 jun. 2005. Aceito em: 9 ago. 2005. 